\title{
Obituary Prof. Dr. Wolfgang Dörr (1959-2019)
}

\author{
Anna. A. Friedl ${ }^{1}$ - Werner Rühm² ${ }^{2}$ Andrzej Wojcik ${ }^{3}$
}

(c) Springer-Verlag GmbH Germany, part of Springer Nature 2020

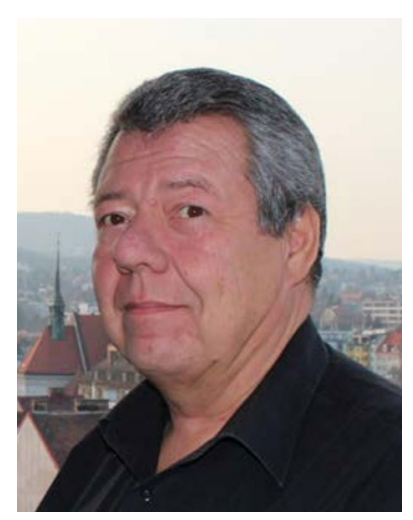

With great sadness we have to announce that Prof. Dr. Wolfgang Dörr, our Editorial Board member, passed away in October 2019, much too early, at the age of 59. Wolfgang Dörr was a great radiation researcher who, above all, importantly contributed to the understanding of mechanisms, risks and prevention of side effects of radiation therapy. A very productive author of scientific publications himself, he was also very active in all the important additional tasks that

make science work-as a member, and frequently also president or chair, of many committees dedicated to advancing modern radiotherapy and radiation protection such as the Austrian Society for Radiation Oncology, Radiobiology and Medical Radiation Physics (ÖGRO); the European Radiation Research Society (ERRS); the European Society for Radiotherapy (ESTRO); the German Society for Radiation Oncology (DEGRO); the German Society for Radiation Research (GBS); and the International Commission on Radiological protection (ICRP) Committee $\mathrm{C} 1$. He was a critical but fair examiner and a dutiful editor and reviewer for several journals, including Radiation and Environmental Biophysics.

We will miss his important insights and constructive contributions to the radiation research field.

Anna. A. Friedl, Werner Rühm and Andrzej Wojcik Editors-in-Chief

Publisher's Note Springer Nature remains neutral with regard to jurisdictional claims in published maps and institutional affiliations.

Anna. A. Friedl

Anna.Friedl@1rz.uni-muenchen.de

1 Ludwig-Maximilians-University of Munich, Munich, Germany

2 Helmholtz Zentrum München, Munich, Germany

3 Stockholm University, Stockholm, Sweden 